
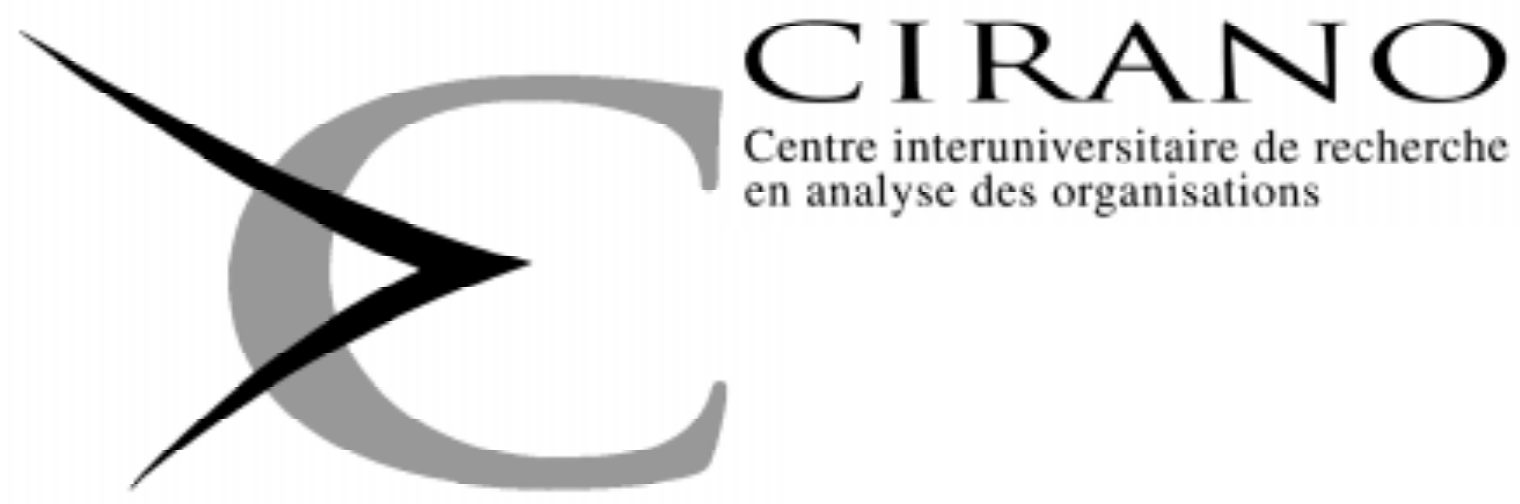

Centre interuniversitaire de recherche en analyse des organisations

Série Scientifique

Scientific Series

95 s-36

SOME RESULTS ON THE

MARKOV EQUILIBRIA OF A

CLASS OF HOMOGENEOUS

DIFFERENTIAL GAMES

Ngo Van Long, Koji Shimomura 


\section{CIRANO}

Le CIRANO est une corporation privée à but non lucratif constituée en vertu de la Loi des compagnies du Québec. Le financement de son infrastructure et de ses activités de recherche provient des cotisations de ses organisations-membres, d'une subvention d'infrastructure du ministère de l'Industrie, du Commerce, de la Science et de la Technologie, de même que des subventions et mandats obtenus par ses équipes de recherche. La Série Scientifique est la réalisation d'une des missions que s'est données le CIRANO, soit de développer l'analyse scientifique des organisations et des comportements stratégiques.

CIRANO is a private non-profit organization incorporated under the Québec Companies Act. Its infrastructure and research activities are funded through fees paid by member organizations, an infrastructure grant from the Ministère de l'Industrie, du Commerce, de la Science et de la Technologie, and grants and research mandates obtained by its research teams. The Scientific Series fulfils one of the missions of CIRANO: to develop the scientific analysis of organizations and strategic behaviour.

\section{Les organisations-partenaires / The Partner Organizations}

-Ministère de l'Industrie, du Commerce, de la Science et de la Technologie.

-École des Hautes Études Commerciales.

-École Polytechnique.

-Université de Montréal.

-Université Laval.

-McGill University.

-Université du Québec à Montréal.

-Bell Québec.

-La Caisse de dépôt et de placement du Québec.

-Hydro-Québec.

-Fédération des caisses populaires de Montréal et de l'Ouest-du-Québec.

-Téléglobe Canada.

-Société d'électrolyse et de chimie Alcan Ltée.

-Avenor.

-Service de développement économique de la ville de Montréal.

Ce document est publié dans l'intention de rendre accessible les résultats préliminaires de la recherche effectuée au CIRANO, afin de susciter des échanges et des suggestions. Les idées et les opinions émises sont sous l'unique responsabilité des auteurs, et ne représentent pas nécessairement les positions du CIRANO ou de ses partenaires.

This paper presents preliminary research carried out at CIRANO and aims to encourage discussion and comment. The observations and viewpoints expressed are the sole responsibility of the authors. They do not necessarily represent positions of CIRANO or its partners.

\section{ISSN 1198-8177}




\title{
Some Results on the Markov Equilibria of a Class of Homogeneous Differential Games ${ }^{*}$
}

\author{
Ngo Van Long ${ }^{\dagger}$, Koji Shimomura
}

\begin{abstract}
Résumé / Abstract
Nous étudions la classe de jeux différentiels dont l'équation de transition et les contraintes sont caractérisées par l'homogénéité du premier degré. Nous prouvons que si la fonction d'objectif possède l'homogénéité du degré $\alpha$, alors la meilleure réponse aux stratégies markoviennes qui possèdent l'homogénéité du premier degré doit avoir la même propriété, et la fonction de valeur est caractérisée par l'homogénéité du degré $\alpha$. On obtient un résultat similaire dans le cas d'une transformation logarithmique de la fonction d'objectif. L'article contient trois exemples.

We consider the class of differential games with transition dynamics and constraints that are homogeneous of degree one. We show that if the integrand of the objective function is homogeneous of degree $\alpha$, then best replies to linear homogeneous Markov strategies are linear homogeneous, and the value function is homogeneous of degree $\alpha$. A parallel result holds when one applies logarithmic transformation to the integrand. Examples are provided.
\end{abstract}

Mots clés : Jeux différentiels, Équilibres markoviens.

Key Words: Differential games, Markov equilibrium.

JEL Classification: $\mathrm{C} 73$

\footnotetext{
Correspondence to: N.V. Long, Department of Economics, McGill University, 855 Sherbrooke Street West, Montreal (Quebec) CANADA H3A 2T7. Fax: 1 (514) 398-4938.

${ }^{\dagger}$ Department of Economics, McGill University and CIRANO.

‡ Research Institute for Economics and Business Administration, Kobe University.
} 


\section{Introduction}

Differential games (and their discrete time counterparts) have been increasingly used by economists to model strategic interactions of economic agents when the state of the system changes over time. Often the strategy space is restricted to include only strategies that condition actions on the current value of the state variables. These strategies are called Markov strategies. Even with this restriction, the multiplicity of Nash equilibria is a common feature of differential games. Equilibrium selection has been a subject of intensive research, and there is a plethora of criteria for selection, with varying degrees of sophistication. In many models, there exist equilibrium strategies that are linear in the state variables. The least that can be said in favor of these equilibria is that linear rules are simple and save computational efforts.

In this paper, we show that for a class of model, best replies to linear strategies are themselves linear. In section 2 , the main propositions are stated and proved. Section 3 contains some examples in continuous time. The discrete time versions of the propositions are stated in Section 4, and an example in discrete time is provided.

\section{The Model in Continuous Time}

We consider a continuous time differential game with two players. (Our results generalize easily to games with $\mathrm{N}$ players.) There are $\mathrm{n}$ state variables and each player has $\mathrm{m}$ control variables. These are denoted by $x \in R_{+}^{n}, c_{1} \in R_{+}^{m}$ and $c_{2} \in R_{+}^{m}$. The evolution of the state variables is given by :

$$
\dot{x}=F\left(x, c_{1}, c_{2}\right),
$$

where $F$ is a vector of $n$ functions, $F_{1}, F_{2}, \ldots, F_{n}$. There are also $h$ inequality constraints:

$$
G\left(x, c_{1}, c_{2}\right) \geq 0
$$

A player $i$ is said to follow a Markov strategy if $c_{i}(t)$ is uniquely determined by the current value of the state variables:

$$
c_{i}(t)=X_{i}(x(t))
$$


where $X_{i}$ is a function from $R_{+}^{n}$ to $R_{+}^{m}$. Player $i$ has the utility function $U_{i}\left(c_{i}\right)$.

Given player $i$ 's Markov strategy $X_{i}$, we define player $j$ 's best reply to $X_{i}$ as a Markov strategy $X_{j}$ such that for all $t$ and all $x(t)$, player $j$ 's integral of discounted utility using $X_{j}$ is at least as great as what he could get under any other alternative strategy $c_{j}(t)=g_{j}(x(t))$. In symbols,

$$
V_{j}(x(t))=\int_{t}^{\infty} e^{-r(s-t)} U_{j}\left[X_{j}(x(s))\right] d s \geq \int_{t}^{\infty} e^{-r(s-t)} U_{j}\left[g_{j}(\bar{x}(s))\right] d s
$$

where $x(s)$ is the solution of

$$
\dot{x}(s)=F\left[x, X_{i}(x), X_{j}(x)\right], s \geq t
$$

with $x(t)$ given, and $\bar{x}(s)$ is the solution of

$$
\dot{x}(s)=F\left[x, X_{i}(x), g_{j}(x)\right], s \geq t
$$

with $x(t)$ given.

A Markov perfect equilibrium is a pair of Markov strategies that are best replies to each other.

We can now state our main result:

Proposition 1 : Assume that $U_{j}$ is homogeneous of degree $\alpha>0$, that $F$ and $G$ are homogeneous of degree one in $\left(x, c_{1}, c_{2}\right)$, and that player $j$ 's opponent uses a Markov strategy that is homogeneous of degree one. Then

(i) Player j's best reply is homogeneous of degree one in $x$.

(ii) $V_{j}(x(t))$ is homogeneous of degree $\alpha$ in $x$.

Proof: Without loss of generality, let $t=0$ and $x(0)=b$. Given $X_{i}$ and given $x(0)=b$, player $j$ 's best reply $X_{j}$ yields a time path for $c_{j}$, which we denote by 


$$
c_{j}(s)=\phi(s, b)
$$

This time path solves the optimal control problem

$$
\operatorname{Max} \int_{0}^{\infty} e^{-r s} U_{j}\left(c_{j}(s)\right) d s
$$

subject to

$$
\begin{gathered}
\dot{x}=F\left[x, X_{i}(x), c_{j}\right], G\left[x, X_{i}(x), c_{j}\right] \geq 0 \\
x(0)=b
\end{gathered}
$$

The associated time path for the state variables is denoted by

$$
x(s)=\psi(s, b)
$$

We claim that if $x(0)=\lambda b \quad(\lambda>0)$, then the control path $\lambda \phi(s, b)$ is feasible and the associated path for the state variables is $\lambda \psi(s, b)$. This is obvious, because $F$ is homogeneous of degree one, and player $i$ 's strategy is, by assumption, homogeneous of degree one.

It remains to prove that, with $x(0)=\lambda b$, the feasible control path $\lambda \phi(s, b)$ is optimal. We use the method of proof by contradiction. Suppose $\lambda \phi(s, b)$ is not optimal for $x(0)=\lambda b$. Then there exists a feasible consumption path $\widetilde{c}_{j}(s)$ such that

$$
\int_{0}^{\infty} e^{-r s} U_{j}\left(\widetilde{c}_{j}(s)\right) d s>\int_{0}^{\infty} e^{-r s} U_{j}(\lambda \phi(s, b)) d s
$$

It follows that, for $x(0)=b$, the feasible control $\frac{1}{\lambda} \widetilde{c}_{j}(s)$ gives the following integral of discounted utility flow :

$$
I=\int_{0}^{\infty} e^{-r s} U_{j}\left(\frac{1}{\lambda} \widetilde{c}_{j}(s)\right) d s=\int_{0}^{\infty} e^{-r s}\left(\frac{1}{\lambda}\right)^{\alpha} U_{j}\left(\widetilde{c}_{j}(s)\right) d s
$$

Therefore 


$$
I>\left(\frac{1}{\lambda}\right)^{\alpha} \int_{0}^{\infty} e^{-r s} U_{j}(\lambda \phi(s, b)) d s=\int_{0}^{\infty} e^{-r s} U_{j}(\phi(s, b)) d s
$$

This is in contradiction with the fact that $\phi(s, b)$ solves the optimal control problem (2.8) subject to (2.9) and (2.10). Thus (i) is proved.

To prove (ii), we note that

$$
V_{j}(b)=\int_{0}^{\infty} e^{-r s} U_{j}(\phi(s, b)) d s
$$

and, from (i),

$$
V_{j}(\lambda b)=\int_{0}^{\infty} e^{-r s} U_{j}(\lambda \phi(s, b)) d s
$$

From $(2.15),(2.16)$ and the assumption that $U_{j}\left(c_{j}\right)$ is homogeneous of degree $\alpha$,

$$
V_{j}(\lambda b)=\lambda^{\alpha} V_{j}(b)
$$

This completes the proof of proposition 1 .

It is easy to adapt the proof of proposition 1 to prove the following result :

Proposition 2: Assume, instead, that $U_{j}=\ln \left[W\left(c_{j}\right)\right]$, where $W\left(c_{j}\right)$ is homogeneous of degree $\alpha>0$. Then, given the other assumptions stated in proposition 1 , the following results obtain:

(i) Player j's best reply is homogeneous of degree one in $x$.

(ii) $V_{j}(x(t))$ satisfies the following property:

$$
V_{j}(\lambda x(t))=\frac{\alpha \ln \lambda}{r}+V_{j}(x(t))
$$

Proof : 
Part (i) : replace (2.13) and (2.14) by

$$
\begin{aligned}
& I=\int_{0}^{\infty} e^{-r s} \ln \left[W\left(\frac{1}{\lambda} \widetilde{c}_{j}(s)\right)\right] d s=-\frac{\alpha \ln \lambda}{r}+\int_{0}^{\infty} e^{-r s} \ln W\left(\tilde{c}_{j}(s)\right) d s \\
& I>-\frac{\alpha \ln \lambda}{r}+\int_{0}^{\infty} e^{-r s} \ln [W(\lambda \phi(s, b))] d s=\int_{0}^{\infty} e^{-r s} \ln [W(\phi(b))] d s
\end{aligned}
$$

Part (ii) : use an argument parallel to the proof of part (ii) of proposition 1.

Corollary : Under the assumption of proposition 2, if $x$ is a scalar (i.e. there is only one state variable) then

$$
V_{j}(x)=\frac{\alpha \ln x}{r}+B
$$

where $B$ is a constant.

\section{Proof :}

Write $\lambda x=x+(\lambda-1) x$. Then, from $(2.18)$

$$
V(x+(\lambda-1) x)-V(x)=\frac{\alpha \ln \lambda}{r}
$$

Divide both sides of $(2.22)$ by $(\lambda-1) x$ and take the limit as $\lambda$ tends to 1 . The resulting left hand side is the derivative of $V$ with respect to $x$, and the right hand side is $\alpha / x r$. This completes the proof.

\section{Some examples}

We now illustrate our results by some examples. 


\subsection{Example 1 : A resource with declining effectiveness.}

Our first example is an instance of a class of problems studied by Cornes, Long and Shimomura (1994). It concerns the long term decline in effectiveness of a pesticide. Let $x(t)$ denote the effectiveness of the pesticide, and $a_{i}(t)$ the rate of application of the pesticide by farmer $i$. There are $N$ farmers. The aggregate rate of application is

$$
a(t)=\sum_{i=1}^{N} a_{i}(t) .
$$

Insects tend to develop resistance to pesticides over time. To capture this feature, we suppose that $x(t)$ declines with aggregate application :

$$
\dot{x}(t)=-a(t)
$$

The decline in effectiveness means that we must distinguish the nominal doses, $a_{i}(t)$, from the effective doses $a_{i}(t) x(t)$. We assume that each farmer's profit is an increasing function of the effective doses that he applies to his field:

$$
\pi_{i}(t)=\left[a_{i}(t) x(t)\right]^{\frac{\alpha}{2}} \quad, \quad 0<\alpha<1
$$

Each farmer wants to maximize the integral of the discounted profit flow:

$$
\operatorname{Max} \int_{0}^{T_{i}} \pi_{i}(t) e^{-r t} d t
$$

It is understood that when $x$ becomes zero, the pesticide becomes worthless. A convenient way to take this into account is to impose the following constraint on problem (3.4) :

$$
x\left(T_{i}\right) \geq 0
$$

We allow each firm to choose its own terminal time $T_{i}$.

While it is possible to solve the above differential game problem directly, it is convenient to transform variables so that proposition 1 can be applied. Define a new control variable

$$
c_{i}(t)=\left[a_{i}(t) x(t)\right]^{\frac{1}{2}}
$$

Then, from (3.2), (3.3) and (3.6) 


$$
\begin{gathered}
\dot{x}(t)=-\sum_{i=1}^{N} c_{i}^{2} / x \\
\pi_{i}(t)=\left[c_{i}(t)\right]^{\alpha}
\end{gathered}
$$

It follow from proposition 1 that farmer $i$ 's best reply is of the form

$$
c_{i}(t)=\beta_{i} x(t)
$$

if all other farmers use linear strategies

$$
c_{j}(t)=\beta_{j} x(t) \quad, \quad j \neq i
$$

In what follows, we focus on a symmetric solution. The Bellman-HamiltonJacobi equation for the representative farmer $i$ is

$$
r V_{i}(x)=\operatorname{Max}\left[c_{i}^{\alpha}+V_{i}^{\prime}(x)\left(-\frac{c_{i}^{2}}{x}-(N-1) \beta^{2} x\right)\right]
$$

where the maximization is with respect to $c_{i}$ and where $\beta_{j}=\beta$ for all $j \neq i$. Applying proposition 1, we write

$$
V_{i}(x)=A x^{\alpha}
$$

and (3.11) becomes

$$
r A x^{\alpha}=\operatorname{Max}\left[c_{i}^{\alpha}-\alpha A x^{\alpha-1}\left((N-1) \beta^{2} x+\frac{c_{i}^{2}}{x}\right)\right]
$$

This yields the first order condition

$$
\alpha c_{i}^{\alpha-1}=2 \alpha A x^{\alpha-1}\left(c_{i} / x\right)
$$

or

$$
c_{i}=x(2 A)^{\frac{1}{\alpha-2}}
$$

Substituting (3.15) into (3.13), and using the assumption of a symmetric solution, we obtain

$$
r A x^{\alpha}=(2 A)^{\frac{\alpha}{\alpha-2}}\left[1-\frac{\alpha N}{2}\right] x^{\alpha}
$$


Since $A$ is non-negative (firms do not make losses in equilibrium), equation (3.16) implies that a symmetric equilibrium in linear strategies exists if and only if $N<\frac{2}{\alpha}$. Under this assumption, the effectiveness of the pesticide declines to zero only asymptotically. The equilibrium time horizon is infinite. Solving (3.16) for $A$ and substituting into (3.15), we obtain the linear strategy

$$
c_{i}=\left(\frac{r}{2-\alpha N}\right)^{\frac{1}{2}} x
$$

provided that $N<\frac{2}{\alpha}$. The nominal doses are

$$
a_{i}=c_{i}^{2} / x=\frac{r x}{2-\alpha N}
$$

As $N$ approaches $\frac{2}{\alpha}$ from below, $a_{i}$ tends to infinity.

\subsection{Example 2 : Exploiting a common pool.}

This example is a special case of the class of problems studied by Clemhout and Wan (1985). Let $x(t)$ denote the stock of oil in a common pool. The $N$ players are the countries that have access to the pool. Their rates of extraction are $c_{i}(t)$, $i=1,2, \ldots, N$. The utility function for player $i$ is $U\left(c_{i}\right)=\ln \left(c_{i}^{\alpha}\right)$. The transition equation is

$$
\dot{x}=-\sum_{i=1}^{N} c_{i}
$$

We assume that the time horizon is infinite, and all countries maximize the integral of discounted utility.

If player $i$ believes that all other players use the strategy

$$
c_{j}=\beta x
$$

then, according to proposition 2, its best reply must be of the form

$$
c_{i}=\beta_{i} x
$$

The Bellman-Hamilton-Jacobi equation for player $i$ is

$$
r V_{i}(x)=\operatorname{Max}\left[\ln c_{i}^{\alpha}+V_{i}^{\prime}(x)\left(-c_{i}-(N-1) \beta x\right)\right]
$$


According to the corollary to proposition 2, $r V_{i}(x)$ must be of the form $A \ln x+$ $B$. Use this in (3.22) to obtain.

$$
r A \ln x+r B=\operatorname{Max}\left[\ln c_{i}^{\alpha}-\frac{A}{x}\left(c_{i}+(N-1) \beta x\right)\right]
$$

The first order condition yields

$$
c_{i}=\alpha x / A
$$

Assuming a symmetric equilibrium, we have

$$
\beta=\alpha / A
$$

Substitute (3.24) and (3.25) into (3.22) to obtain

$$
r A \ln x+r B=\alpha \ln x+\ln (\alpha / A)^{\alpha}-\alpha N
$$

Since the above equation must hold for all $x>0$, it follows that

$$
\begin{gathered}
A=\alpha / r \\
r B=\alpha \ln (\alpha / A)-\alpha N
\end{gathered}
$$

The equilibrium rate of extraction is therefore

$$
c_{i}(t)=r x(t)
$$

It is interesting to observe that the strategy (3.29) is independent of the number of players. This contrasts sharply with (3.17). Finally, from (3.29) and (3.19),

$$
\dot{x} / x=-r N
$$

\section{The Discrete Time Versions}

It is clear that propositions 1 and 2 also apply in discrete time. The only modifications are that $(2.1)$ and $(2.4)$ are replaced by their discrete time counterparts:

$$
x(t+1)-x(t)=F\left(x(t), c_{1}(t), c_{2}(t)\right)
$$




$$
V_{j}(x(t))=\sum_{s=t}^{\infty} U_{j}\left[X_{j}(x(s))\right] b^{s-t}
$$

where $0<b<1$ is the discount factor.

An example : Exploitation of renewable resources.

Consider a pool in which two species of fish coexist. Let $X_{t}$ and $Y_{t}$ denote the current stocks, and $C_{t}$ and $D_{t}$ the corresponding rates of harvest. We assume that

$$
\begin{aligned}
& X_{t+1}=\left(X_{t}-C_{t}\right)^{\alpha_{1}} Y_{t}^{\beta_{1}} \\
& Y_{t+1}=\left(Y_{t}-D_{t}\right)^{\alpha_{2}} X_{t}^{\beta_{2}}
\end{aligned}
$$

where $1>\alpha_{i}>0$ while $\beta_{i}$ can be positive or negative. If both $\beta_{1}$ and $\beta_{2}$ are negative, the two species are said to be mutually competing; if both $\beta_{i}$ are positive, they are symbiotic species; while if $\beta_{1}$ is positive and $\beta_{2}$ is negative, then $X$ are the predators and $Y$ are the preys. Our formulation slightly differs from that of Fischer and Mirman (1992a, 1992b), who assume that both $C_{t}$ and $D_{t}$ appear in each growth equation. We will focus on the special case where $\alpha_{i}+\beta_{i}=1$, which was not considered by Fischer and Mirman.

Assume that there are two countries that have common access to the fishing pool. Their rates of catch are $C_{i t}$ and $D_{i t}, i=1,2$, such that, by definition

$$
\begin{aligned}
& C_{1 t}+C_{2 t}=C_{t} \\
& D_{1 t}+D_{2 t}=D_{t}
\end{aligned}
$$

Suppose that country $\mathrm{i}$ believes that country $\mathrm{j}$ follows the linear fishing rules :

$$
\begin{gathered}
C_{j t}=\gamma_{j} X_{t} \\
D_{j t}=\delta_{j} Y_{t}
\end{gathered}
$$

If we assume that utility functions are 


$$
U_{i}=\ln C_{i}+\ln D_{i}
$$

for $i=1,2$, then it follows from our proposition 2 that the best reply is homogeneous of degree one in the stocks. This can be explicitly calculated by considering a value function of the form

$$
V_{i}=A_{i} \ln X+B_{i} \ln Y+E_{i}
$$

The Bellman equation is

$$
V_{i}\left(X_{t}, Y_{t}\right)=\operatorname{Max}\left[\ln C_{i t}+\ln D_{i t}+b V_{i}\left(X_{t+1}, Y_{t+1}\right)\right]
$$

Substituting (4.7), (4.8) into (4.3), (4.4), and maximizing the right-hand side of (4.11) with respect to $C_{i t}$ and $D_{i t}$ give

$$
\begin{aligned}
& \left(1+b \alpha_{1} A_{i}\right) C_{i}=X\left(1-\gamma_{j}\right) \\
& \left(1+b \alpha_{2} B_{i}\right) D_{i}=Y\left(1-\delta_{j}\right)
\end{aligned}
$$

Substituting (4.12) and (4.13) into (4.11), we obtain the following equations

$$
\begin{aligned}
& A_{i}=1+b \alpha_{1} A_{i}+b \beta_{2} B_{i} \\
& B_{i}=1+b \alpha_{2} B_{i}+b \beta_{1} A_{i}
\end{aligned}
$$

Solving for $A_{i}$ and $B_{i}$

$$
\begin{aligned}
& A_{i}=\left(1-b \alpha_{2}+b \beta_{2}\right) / \triangle \\
& B_{i}=\left(1-b \alpha_{1}+b \beta_{1}\right) / \triangle
\end{aligned}
$$

where

$$
\triangle=\left(1-b \alpha_{1}\right)\left(1-b \alpha_{2}\right)-b^{2} \beta_{1} \beta_{2}
$$

In what follows we assume that $\triangle>0$ and that

$$
\alpha_{i}-\beta_{i}<1
$$


so that both $A_{i}$ and $B_{i}$ are positive. It follows that the best reply strategies of country $i$ are linear :

$$
\begin{aligned}
& C_{i}=\gamma_{i} X \\
& D_{i}=\delta_{i} Y
\end{aligned}
$$

where

$$
\begin{aligned}
\gamma_{i} & =\frac{\left(1-\gamma_{j}\right)}{1+b \alpha_{2} A_{i}} \\
\delta_{i} & =\frac{\left(1-\delta_{j}\right)}{1+b \alpha_{2} B_{i}}
\end{aligned}
$$

Furthermore, as it is clear that $A_{i}=A_{j}=A$ and $B_{i}=B_{j}=B$, we must have $\gamma_{i}=\gamma_{j}=\gamma$ and $\delta_{i}=\delta_{j}=\delta$, i.e. the linear strategies are necessarily symmetric :

$$
\begin{gathered}
\gamma_{i}=\gamma_{j}=\gamma=\frac{1}{2+b \alpha_{1} A}<\frac{1}{2} \\
\delta_{i}=\delta_{j}=\delta=\frac{1}{2+b \alpha_{2} B}<\frac{1}{2}
\end{gathered}
$$

From (4.3), (4.4), (4.7), (4.8), (4.20), (4.21), (4.24) and (4.25), the evolution of the system is given by

$$
\begin{aligned}
X_{t+1} & =\left[X_{t}(1-2 \gamma)\right]^{\alpha_{1}} Y_{t}^{\beta_{1}} \\
Y_{t+1} & =\left[Y_{t}(1-2 \delta)\right]^{\alpha_{2}} Y_{t}^{\beta_{2}}
\end{aligned}
$$

Let

$$
\begin{aligned}
& x=\ln X \quad, \quad y=\ln Y \\
& \lambda=-\ln (1-2 \gamma)>0 \\
& \mu=-\ln (1-2 \delta)>0
\end{aligned}
$$

The system (4.26) and (4.27) can be written as 


$$
\begin{aligned}
& x_{t+1}=\alpha_{1} x_{t}+\beta_{1} y_{t}-\lambda \\
& y_{t+1}=\beta_{2} x_{t}+\alpha_{2} y_{t}-\mu
\end{aligned}
$$

This system is equivalent to the following second order difference equation in $x$

$$
x_{t+2}-\left(\alpha_{1}+\alpha_{2}\right) x_{t+1}+\left(\alpha_{1} \alpha_{2}-\beta_{1} \beta_{2}\right) x_{t}=-\lambda-\beta_{1} \mu
$$

Since $\beta_{i}+\alpha_{i}=1$, the characteristic equation of (4.33) has two roots, $r_{1}=1$, and

$$
-1<r_{2}=\alpha_{1}+\alpha_{2}-1<1
$$

The general solution of (4.33) is of the form

$$
x_{t}=E+F t+G\left(\alpha_{1}+\alpha_{2}-1\right)^{t}
$$

where $E$ and $G$ are arbitrary constants, and

$$
F=\frac{-\lambda-\left(1-\alpha_{1}\right) \mu}{2-\alpha_{1}-\alpha_{2}}<0
$$

Therefore $x$ will tend to minus infinity, implying that $X$ will tend to zero, as $t$ tends to infinity. A similar argument shows that $Y$ will also tend to zero.

We have shown that along the Markov equilibrium path, both species are driven to extinction. It can be shown that if the two countries cooperate to maximize the sum of their utility flows, extinction is also optimal, but exploitation will be at a slower rate. 


\section{Acknowledgment :}

The authors thank Andrea Gaunersdorfer, Ted Sieper and Gerhard Sorger for their helpful comments. Financial supports from FCAR and SSHRC are gratefully acknowledged.

\section{References}

[1] Clemhout, Simone and Henry Wan, Jr., 1985, Dynamic common property resources and environmental problems, Journal of Optimization Theory and Applications, 46, 471-481.

[2] Cornes, Richard, Ngo Van Long and Koji Shimomura, 1994, Intertemporal productivity externalities : drugs and pests, Unpublished typescript.

[3] Fischer, Ronald and Leonard Mirman, 1992a, Strategic dynamic interaction, Journal of Economic Dynamics and Control, 16, 267-287.

[4] Fischer, Ronald and Leonard Mirman, 1992b, The complete fish wars : biological and dynamic interactions, to appear in Journal of Environmental Economics and Management. 